\title{
PROBLEMS AND SOLUTIONS
}

\author{
EDITED BY MURRAY S. KLAMKIN \\ COLlaborating EdITORS: HENRY E. FETTIS \\ YUDELL L. LUKE \\ CECIL C. ROUSSEAU \\ OTTO G. RUEHR
}

All problems and solutions should be sent, typewritten in duplicate, to Murray S. Klamkin, Department of Mathematics, University of Alberta, Edmonton, Alberta, Canada T6G 2G1. An asterisk placed beside a problem number indicates that the problem was submitted without solution. Proposers and solvers whose solutions are published will receive 10 reprints of the corresponding problem section. Other solvers will receive just one reprint provided a self-addressed stamped (U.S.A. or Canada) envelope is enclosed. Proposers and solvers desiring acknowledgment of their contributions should include a self-addressed stamped postcard (no stamp necessary outside the U.S.A. and Canada). Solutions should be received by February 15, 1984.

\section{PROBLEMS}

\section{Two Legendre Polynomial Identities}

Problem 83-16, by A. D. RAWLINS (Brunel University, Middlesex, UK).

Show that

$$
\begin{aligned}
P_{n}\left\{x\left(x^{2}-\alpha^{2}\right)^{-1 / 2}\right\}= & \frac{(-1)^{n}}{n !}\left(x^{2}-\alpha^{2}\right)^{(n+1) / 2} \frac{d^{n}}{d x^{n}}\left(x^{2}-\alpha^{2}\right)^{-1 / 2}, \quad n \geqq 0, \\
P_{n}\left\{\frac{1+B x}{B+x}\right\}=B^{-1}(n !)^{-2}\left\{\frac{-(B+x)}{2}\right\}^{n+1} & \cdot \prod_{p=1}^{n}\left\{-\frac{d}{d x}\left[\left(1-x^{2}\right) \frac{d}{d x}\right]-p(p-1)\right\}\left\{\frac{x-B}{x+B}\right\}, \quad n \geqq 1 .
\end{aligned}
$$

\section{A System of Probabilistic Inequalities}

Problem 83-17*, by T. TEN RAA (Erasmus University, Rotterdam, The Netherlands).

Consider $n$ locations, $n \geqq 2$ :

$$
\bigcirc_{1} \bigcirc_{2} \cdots \bigcirc_{i} \cdots \bigcirc_{j} \cdots \bigcirc_{n}
$$

Initially, there is one particle at each location. Then there are two consecutive transitions, governed by real nonnegative matrices $\left(p_{i j}\right)$ and $\left(x_{i j}\right)$, respectively. Thus $p_{i j}$ is the probability that the particle which is originally at location $i$ will move to $j$ in the first round. Similarly, $x_{i j}$ is the probability that a particle which after the first round is at location $i$ will move to $j$ in the second round.

It is assumed that the system is shaky. More precisely, all particles move with certainty in both rounds. Furthermore, in the second transition any particle has a positive probability to reach any other location. Formally,

$$
\begin{array}{llll}
p_{i i}=0, & p_{i j}>0 & \text { for some } j \neq i, & i=1, \cdots, n, \\
x_{i i}=0, & x_{i j}>0 & \text { for all } j \neq i, & i=1, \cdots, n .
\end{array}
$$

(It is not necessary to assume that transition probabilities add up to unity.)

Consider the particle which originates from any location $i$. The probability that it 